\title{
Meta-operations, autopoiesis and neo- systems thinking: what significance for spatial planners?
}

Article

Accepted Version

Chettiparamb, A. (2018) Meta-operations, autopoiesis and neo-systems thinking: what significance for spatial planners? Planning Theory, 17 (4). pp. 628-643. ISSN 1741-3052 doi: https://doi.org/10.1177/1473095218782816 Available at https://centaur.reading.ac.uk/77463/

It is advisable to refer to the publisher's version if you intend to cite from the work. See Guidance on citing.

To link to this article DOI: http://dx.doi.org/10.1177/1473095218782816

Publisher: Sage

All outputs in CentAUR are protected by Intellectual Property Rights law, including copyright law. Copyright and IPR is retained by the creators or other copyright holders. Terms and conditions for use of this material are defined in the End User Agreement.

www.reading.ac.uk/centaur

\section{CentAUR}


Central Archive at the University of Reading

Reading's research outputs online 


\title{
Meta-operations, autopoiesis and neo-systems thinking: what significance for spatial planners?
}

Author: Dr Angelique Chettiparamb, Real Estate and Planning, University of Reading. Email: a.chettiparamb@reading.ac.uk

\begin{abstract}
This essay introduces the theory of legal autopoiesis to planning. It discusses the main tenets of neo-systems thinking and elaborates on select claims and concepts from legal autopoiesis for planners. The claims and concepts are then used to re-analyse a published case study describing the after effects of the implementation of a Compulsory Purchase Order in the regeneration of the Docklands in Cardiff. The re-interpretation draws attention to the added insights brought into focus by the theory. The significance of neo-systems thinking for planning is then discussed. The paper concludes that the new epistemological framings connects the universal to the particular with implications for current understandings of planning concepts such as public interest, consensus, situatedness, contingency and justice. The article argues that neo-systems thinking deconstructs 'how to' dilemmas for planners from a non-normative standpoint at a meta-operational level.
\end{abstract}

Keywords: legal autopoiesis, neo-systems thinking, meta-operations, compulsory purchase orders.

\section{Introduction}

The theory of autopoietic social systems proposed by Niklas Luhman has attracted attention across the various disciplines in the social sciences on a number of counts. The theory has divided academic opinion, with some seeing it as highly innovative and ground breaking, whilst others have received it with a good deal of scepticism. The word 'autopoieisis' is translated from Greek and coined from two words, 'autos' meaning 'self' and 'poiein' meaning 'to make' (Brans and Rossbach, 1997, p.425). The word therefore means 'self-producing'. The theory, puts forward a conception of the social world as constituted of self-referential and selfproducing social functional systems i.e. the outputs of the system constitutes its own inputs. Functional systems, such as the legal system, the political system, economic system, etc., according to the theory are formed by internal differentiation of the social system which in turn enable the social system to deal with complexity. These ideas are further elaborated in the next section. 
One of the main sticking points of contention of the theory has been Luhmann's insistence on strict autopoietic operations of the various social functional systems. A self-referential operation by definition seems to remove engagement with any moral/value dimensions or even motivational issues in its explanation of society. This has led to the theory being referred to as 'anti-humanist', 'anti-normative' and 'anti-individual' (King and Thornhill, 2003, pgs, 2 and 69). Further, Luhmann also expressly states that no functional system can ever directly cause a change in another functional system. This is counter-intuitive, and it poses questions and creates ambiguities regarding causal relationships. The theory has therefore been also described as 'post-instrumental' (Paterson, 2006, p.15).

Planning thought has engaged with the theory of autopoiesis with authors attempting to discern and formulate the contribution it might make to current understandings in planning. This essay is another attempt in this direction. Previous attempts have engaged with the viability of the idea of planning itself (van Assche and Verschraegen, 2008), insights the theory offers for the micro-dynamics of public participation (Chettiparamb, 2007a) and change or co-evolution (Chettiparamb, 2007b, van Assche et. al, 2012). This paper engages with the functional system of law in particular, and delves on its autopoiesis seen and analysed from a planning perspective, in order to discern how this might guide planners in their professional lives. The paper adopts an unconventional method of re-analysing a published case study to make visible a re-configured interpretation. Methodologically this means that this author only has access to case information included by the original authors in their publication. No new empirical facts are added. The contribution of a new article following this method then arises from the new positioning of published empirical material. In this article, the reinterpretation uses insights from the theory of autopoiesis. In doing so, it draws attention to the added insights that are yielded by this theory. It must be noted that the aim of the article is not to add to knowledge of the legal profession, but instead it aims to reconceptualise the working of law in planning as seen from the planning profession.

The next section discusses some general ideas that define the theory. It introduces the reader to the rather complex and unfamiliar terminologies that make up the theory of autopoietic social systems. The secondary case study is then introduced and summarised from the published article. The section after focuses on the autopoiesis of law in some detail which is then used to 
reinterpret the case study. Finally, the significance of the reinterpretation of the case study for the discipline of planning is discussed before the conclusion which reiterates the main points.

\section{Social autopoiesis: A brief outline}

The theory of autopoiesis takes complexity of society seriously and offers an account of differentiation, coding, observation, selection, programming, and structural coupling which are, according to the theory, mechanisms through which social functional systems reduce complexity in order to be able to deal with it. The theory proposes a model of the social system defined by 'communications' which are identified as the main elements of reproduction of society: society is reproduced by the reproduction of communications. Social systems are also imagined as different from psychic systems (individuals), where the autopoietic element is 'thought' and biological systems, where the autopoietic element is 'life' (Luhmann, 1995).

For Luhmann, 'modern' society is constituted of differentiated functional sub-systems such as the economic system, political system, legal system, etc. each of which are characterised by a unique binary code that distinguishes the operations of a particular functional system from the operations of the rest of society. For instance, the economic system is said to be coded by have/have not, the political system by power/no power, and legal system by legal/illegal binaries. The unique codes mark each functional system as operationally closed, but cognitively open to the environment of the functional system. Each functional system may therefore observe other systems and construct meanings from events that happen in the environment (cognitively open), but these observations and interpretations will always only be guided by the application of the functional system's own binary code (operationally closed). The environment for each system consists of all other functional systems as well as psychic systems. Thus, individuals within society, events in the environment and communications in other functional systems are all argued to at most produce perturbations for the autopoietic functional systems. The self-referential binary code ensures that the functional system in question will always only respond to these perturbations on terms that are decided by the functional system itself (Luhmann, 1995). Luhmann, (1991, pg 177) points out -

"in a functionally differentiated society, it will have to be accepted above all that perspectives and distinctions and processes differ according to the system one starts from, that is, according to the point one observes society from, and treats the various other systems as environment".

Since there is no privileged position of 'objectivity' in such a schema of observation (all observations are made by some system), the theory argues against the existence of universal 
values or structures. This kind of strict functional differentiation however is argued to be a phenomenon of the more 'complex' or 'modern' societies (Luhmann, 2004).

One advantage of the operative closure and non-discriminatory use of a code is of course the certainty that it provides. According to Luhmann, the functional contribution of the legal system to society is not in providing 'social control' or 'integration' - as may have been hitherto argued in social theory - but in providing this certainty. In other words, the legal system manages broad societal (as opposed to individual) expectations over time, by providing certainty. The certainty provided by the legal system helps to structure society communications as the application of the code is assured. The operative closure of the legal system guarantees the legal system its autonomy for the legal system then only refers to itelf. This autonomy coupled with 'cognitive openness' allows the legal system to develop 'requisite variety' in its internal structure through 'learning' in order to carry out functional roles in society (Luhmann, 1995). This will be elaborated and illustrated in the case study discussion to follow.

The basic tenets of the theory of autopoiesis are provided above. In the next section, a published secondary case study is summarised. Substantively, the case problematizes the application of law in a situation of interest to planning. After the presentation of this case, further concepts from legal autopoiesis will be discussed.

\section{Planning and Law: Summary of a Case Study}

For a theory, such as autopoiesis that puts forward a different conception of how society works and attempts to describe social dynamics in all social spheres of modern society, any empirical situation, should lend itself to theoretical analysis. The choice of this case study therefore is not primarily based on theoretical concerns but is instead based on the following methodological concerns. First, a secondary case study of sufficient empirical detail is required. Much work in planning and law is descriptive, historical or normative (for example see Salet, 2002, Booth 2003, 2002, 1999, Herbert-Young, 1998). Empirically rooted, casestudy based work showcasing and providing detailed evidence for claims, which is needed for this methodological approach, is not that common. Second, this case study was chosen for its focus on a functional system, here the working of law, its implications for planning and the social dynamics it gives rise to in implementation. Third, the case study was also chosen as it advocates a social interpretive view of law that appears opposed to the rather impersonal theory of autopoiesis. This provided an opportunity for a radically different re-conceptualisation. The 
case therefore presents an interesting medium for unraveling the insight that the theory of autopoiesis might provide to planners when they confront law. It must be noted that the article is not very recent and the empirical descriptions were interpretations of the original authors at a particular point in time.

The case describes the application of a Compulsory Purchase Order in the urban regeneration of the Bay area of Cardiff. A Compulsory Purchase Order in the UK is a legal instrument used by statutory bodies "to compulsorily purchase land to carry out a function which Parliament has decided is in the public interest" (DCLG, 2004, p.6). Such purchases must follow due process and anyone with a right over the land thus taken, is eligible to receive compensation. The instrument is deeply contentious for the impact it can have on those affected (Riley, 2009).

Imrie, $R$ and Thomas,H, (1997) 'Law, Legal Struggles and Urban Regeneration: Rethinking the Relationships' In Urban Studies, Vol 34 No 9, Pgs 1401-1418.

The case study reports on the 'socio-legal process' (pg 1401) associated with the use of the Compulsory Purchase Order (CPO) in UK as a tool for urban regeneration by examining its enforcement in the regeneration of South Cardiff. The CPO is introduced as adversarial in nature, in "which the state seeks to acquire someone's property without their consent" (pg 1401). Following Blomley and Clark, (1990), the authors aim to illustrate that the influence of law "is often mediated through apparently neutral discourses in jurisprudence or even common sense" and that "the role of law in these circumstances is not obvious, mechanical, or automatic" (pg 1415). This, as explained earlier, is diametrically opposed to the theory of autopoiesis which suggests that law is self-referential and its functional aim is to provide stability to expectations.

The initial part of the paper citing studies, stresses "the importance of developing a critical stance towards the role of law and legal mechanisms in underpinning and supporting contemporary forms of urban regeneration" (pg 1402). The "claimed value-neutrality of the Anglo-American tradition of law and legal processes" is challenged (pg 1403) and following Blomley (1994) alternate ways of conceiving the value neutrality are outlined. This is referred to as the 'interpretive paradigm' and is contrasted against the 'socio-technical paradigm'. The contrast is explained as seeing law as 1) local knowledge, not placeless principles, contrasted against universal and applicable to all socio-historic contexts; 2) constitutive of social life not 
reflective, contrasted against determining social life and reflective of social structures; 3) inherently evaluative and potentially indeterminate, contrasted against abstract, determinate, known and relatively fixed; 4) comprised of multiple, competing ideologies, contrasted against a form of higher rationality which is handed down; and 5) comprised of knowledge which is the product of diversity and competing views, contrasted against a form of expertise requiring public deference (pg 1404).

The next part of the paper discusses the CPO itself and its use in the Docklands regeneration. The authors provide a background of the project and the context in which the CPO came to be used: to acquire land needed for the development of the area by a quango, the Land Authority for Wales, and sell it en masse to the developer chosen for the project. The case-study focuses on the displacement of small firms and business in the area and their resistance to forceful eviction brought about through the use of the CPO. Using quotes, the authors report that the firms were more resistant to the manner the eviction was implemented rather than the project itself. This is attributed, by the authors, to the completeness of the hegemonic discourse that accompanied the regeneration project (pg 1408). Objection to the manner of implementation focused on the speed of implementation of the eviction, which followed a timetable prepared without consultation resulting in a schedule that did not allow small firms enough time to find alternate sites that suited various specific needs. This effectively 'criminalised' them, when by doing nothing illegal per se, they still became illegal, just by not complying with the time-table set, primarily due to the impossibility of it. The authors also take issue with the lack of differentiation between different types of firms and the ways in which they were tied to particular sites, as this sometimes resulted in serious damage to the future of particular businesses. The optimism and hope of some of the firms to find recourse in law were revealed as unfounded as their objections were heard through public inquiry presided over by an inspector, who was ultimately responsible to the political/bureaucratic interests that were attempting to promote the project. At the same time some firms used the legal process as an attempt to lever concessions, an approach these firms termed as being 'realistic'. The authors report -

"In the Atlantic Wharf case, we find, on the one hand, the representation of the legal process as universal and partial being used to justify the ignoring of specificities of individual needs and circumstances of small firms affected by the scheme; while on the other hand, the justification of the CPO hinges on an interpretation of the "public interest' which is, of its essence, deeply rooted in the local political milieu" (pg 1407, 1408). 
Connected issues with respect to the ambit of the use of CPO are also discussed: interests that are excluded even when they are affected (due to proximity, linkages with the area); access to resources needed to fight legal battles; the hegemony of 'legal-speak' that excludes people; differences in use values of property; delays of adjudication processes and so on. These issues are not detailed here as the focus in this essay is on the role of the legal system seen from within neo-systems thinking. The authors of the case study advance a view that argues for the embedded nature of law, which makes it an interpretive practice rather than a neutral discourse. They argue -

"these interpretations are contested social practices - they are not automatic applications of some universal prescriptions to straightforward cases- and to present them as anything else is ideological, in the sense of promoting a particular set of beliefs or practices as in the common good (or as neutral) when in reality it benefits certain interests. Moreover, the application of law, as the case indicates, is not neutral or objective yet, paradoxically contrives to deny the

very subjectivities of the legal subjects that it intercedes with" (p. 1416).

Still later however, the authors concede that "in specific cases, the independence and integrity of the law itself can be a powerful brake on the advantages accrued by the socially powerful" (p. 1416).

This essay seeks to understand how the tension between 'independence and integrity' of law, a common perception, is to be resolved with an empirical admittance of social specificity that we find on closer examination of its application. An explanation rooted in 'power' is generally advanced (as is suggested in this case study) and is informative to a certain extent. However, it still leaves open the question of what actually happens when power is activated in a case like the above? What are the dynamics through which power comes to be influential? Explanation/s are normally grounded in either agency, focusing on actions and motivations or are grounded in social structures that condition or steer agency. This essay will argue that grounding in the social systems level will makes it possible to 1) recognize certain dynamics when they do come into play, 2) acknowledge the limitations that a particular situation sets; and 3) reflect on possible ways in which one might deal with such dynamics. These are very central for a discipline rooted in intervention such as planning.

\section{Autopoietic Concepts on the Coding of Legal Systems}

Building on the general description of autopoietic systems provided earlier, more detailed and specific concepts from legal autopoiesis that can help relate to the case study is provided in this section. Not all the concepts related to legal autopoiesis will be discussed here due to shortage of space. The concepts of coding, programming, observation, rejection values and justice are 
used and expanded upon as they will suffice to illustrate the re-interpretation that the theory facilitates and thereby what it might bring to planning. After this section, the case will be reinterpreted.

As mentioned earlier, in a legal system, the binary code operating is the legal/illegal distinction. This distinction in systems theory does not carry any moral overtones, but just denotes the possibility and necessity of choosing between the two.

"The terms legal and illegal thus denote nothing other than the universal system of valuation intrinsic to law, which all operations of the legal system and only operations of the legal system come under" (Luhmann, 1991, p. 147).

A decision as to which value to adopt is entirely contained within the legal system, taking place in the context of operations within that system, and is not an a priori attribute of the event itself. Thus

"assignment to the values of legal or illegal is not possible either as an isolated event (with no connection with other operations in the legal system) or as an event within the environment of the legal system" (Luhmann, 1991, pg 146).

In every case where legal or illegal is decided, the system refers to itself. Any observation of any event is made from within the functional system. The binary code of the functional system will always distort the observation and the description provided. Therefore, though the law has only a strict two-value coding, other systems may assign different meanings to events and incidents depending on which system is making the observation. Then,

"even the mere distinction between legal and illegal could then count as a hostile act, a breach of the harmony of co-existence in good will” Luhmann (1991, pg 147).

This form of stark application of the binary code happens only when the legal functional system is 'matured' - differentiated enough from other systems be it religious, economic or politics. If this is not the case, the legal system will not operate strictly on its own code as happens when questions of legality/illegality are decided by the political system or the religious system.

With regard to time, Luhmann stresses the present. Though legal validity has normally been argued hierarchically in that actions gain validation by recourse to 'higher' or 'lower' principles, the theory of autopoiesis substitutes such a premise with temporal validity or as Luhmann calls it 'time-binding' (Luhmann, 2004, p. 72). Thus, law gains validity by securing expectations so that one operation of the law is connected to the next in autopoietic reproduction.

"For everything that happens, is happening now - and not in the past or in the future. Time horizons are empty horizons in relation to what is actually happening, and the only purpose 
they serve is to orient the present and move along with it" (Luhmann, 2004, p.131, original italics).

If contingency is defined as "everything that is neither necessary nor impossible" (Luhmann, 1992, pg 96, quoted in Gumbrecht, 2001, pg 52), then the legal system cannot predict what sort of complex web of contingencies may come up in the future. It can only speak about the application of the code on particular courses of actions, as and when they are observed. One therefore does not know in the strict sense what is legal or illegal in the future. This level of assurance for expectations can be provided by the legal system if, and only if, it is bound up by norms.

"we will call expectations not disposed toward learning norms. When disappointed, they are counterfactually retained" (Luhmann, 1995, pg 321, original italics).

The function of the legal system in society is then to maintain such expectations even in the face of disappointment. Other functional systems such as religion or morality also deal with norms, but law deals with norms using the unique code of legal/illegal. It compares facts selected by the legal system with norms that are also pre-selected and coded by the legal system, thus achieving operational closure. Other norms, be it from custom, religion or morals, are not considered by the legal system as norms, though they may be treated as facts if the legal system can process it using its own code (Nobles and Schiff, 2004). For an individual then, the moral basis of legality/illegality might appear to be intertwined and unclear while for the law which deals with it in the present, the distinction is just one of legality/illegality.

"It is only in the individual's fate that the code solidifies into a provision about one value and not the other; and only then does it emerge that particular conduct or particular claims are, with far-reaching consequences, lawful (unlawful), and not the opposite" (Luhmann, 1991, pg 149).

The operations of the legal system can be observed either internally by the legal system itself or externally by other functional systems in the environment. As all observations can only take place from within a functional system using its own code, this observation introduces another binary code (besides the legal/illegal code of the legal system). For instance, the code could be the power/no power code of politics or the have/have not code of economics, depending on which functional system is observing. When the legal system observes itself, it introduces a 'rejection value' through which it decides whether it is legal/illegal to apply its own binary code. The binary code of the legal system by itself is not negated in this self-observation. What is introduced instead is a code that decides if the legal system must be brought into play at all. As Luhmann (1991, pg 157,158) clarifies - 
"what is rejected is the criticality.... of the codes of other systems for the given system, not the relevance of their valuations" (original italics).

When an external functional system observes the legal system, it will do so by using its own code. For instance the operations of the legal system may be observed by the political system and this observation might trigger operations within the political system that use the code power/no power or it might be observed by the economic system and trigger its own operations of have/not have. Luhmann terms this as an 'irritation' on the functional system concerned, as no functional system can directly determine or cause a change in another system. When such irritations in the environment of the legal system are common through repeated occurrences, the legal system can presuppose the occurrence and thus get 'structurally coupled' to another functional system. Structurally coupled systems do not cause or determine outcomes in one another, but they are a constant irritant to each other, due to which they can develop additional structures to respond to the irritant albeit in their own terms.

"By replacing direct influence or undifferentiated forms of communication with separate systems and structural couplings, systems maybe said to both reduce and facilitate their influence upon each other. We can talk about reduction, because a system that determines through its own operations what aspects of other systems it will recognize may be said to have reduced its sensitivity to those other systems. We can talk about facilitation, if the inability of one system to determine whether and how it will register within another system enables both systems to increase their variety (complexity)" (Nobles and Schiff, 2004, p.43).

Programming allows a functional system to attain some flexibility even when the code remain inflexible. According to Nobles and Schiff $(2004,17)$, in legal theories these might be called 'rules' of law. Conditional programmes are one type of programme that the legal system uses to manage contingencies. Within the legal system, these are of the form 'if fact $\mathrm{X}$ is legally established, then $\mathrm{Y}$ is legal' or 'if fact $\mathrm{X}$ is legally established, then $\mathrm{Z}$ is illegal'. All functional systems also have to maintain a degree of cognitive responsiveness to the environment in order to develop internal mechanisms for its own structural change. They do this by employing a 'formula' to deal with contingencies that trigger change in the programmes of the system. This 'formula' is employed in observing the conditional programmes and ensuring that they are dealt with equally. For the legal system the norm of justice fulfils this purpose. According to Luhmann (2004), it is a formula that the legal system employs to observe itself and uses to trigger internal structural changes. Justice is equated to the binary value of equal/unequal, with 'equal' being read as treating like cases alike. The concept of 'justice' thus allows the legal system to self-observe, revisit/change past programmes that apply the binary code and also develop new conditional programmes such that expectations are maintained even when 
disappointed. Thus justice allows the legal system to continue to maintain 'time-binding' through expectations (Luhmann, 2004).

"Justice does not guide the development of the legal system in the manner that advocates of reform might expect. It does not become more just, or realize ever greater levels of equality. The application of the distinction equal/unequal has, like the binary code legal/illegal, no third quality or value that determines what lies on either side" (Nobles and Schiff, 2004, p.23).

To summarise this section, first, in society all observations are made from within a functional system and there is no universal viewpoint for objective observation; second, in a legal system, the code is legal/illegal and the system uses this code for all operations; third, even while the strictness of the code guarantees a measure of certainty, all operations are bound to the present; fourth, the legal system cannot predict the web of contingencies that might arise in the future and therefore cannot predict the associated expectations; fifth, the legal system observes itself and this introduces a rejection value which does not negate the code as such, but decides on whether the code itself must be applied or not; sixth, functional systems can get structurally coupled and produce irritations for each other, though they cannot determine outcomes in the other system; seventh, stability for expectations is managed through programming; and eighth, the legal system maintains a degree of responsiveness to the environment by employing the formula of 'justice' which ensures that decisions are 'equal' in the sense of like cases being treated alike. I now return to the case study to re-analyse it using the above claims and concepts.

\section{Re-analysis of the Case Study Using Autopoiesis}

In this re-analysis, the case study is reconstructed in specific ways, different from the framework used by the authors. The first claim to advance is that the strict binary code of the law was indeed used by the quango, in this case, the Land Authority for Wales (LAW),. This is evidenced through the quote from one of its agents:

"we had the law on our side, we had followed the rule book and sure it was a tight deadline but that was no reason for some of them to break it... they had no chance for resisting it" (p. 1409).

The agent here is banking on the security provided by the law knowing that the law would not take into account any other distinction. The perceptions and experience of the firms involved mirror the above. Thus:

"there was no latitude for common sense... they just did it by the law and letter... We went to the public inquiry and tried to fight the $\mathrm{CPO}$ on the grounds that it would destroy jobs and 
our business... the case was a foregone conclusion before we entered the courtroom" (pg 1411).

Those who tried to lever benefits from the acquiring authority - a group of property owners who saw the political forces as stronger that they could ever be - also perceived the certainty of law, aligning their expectations to what they saw as a legal inevitability. Thus,

"we didn't care for the CPO and we protested knowing we had no control over it. We just had to be realistic" (pg 1411).

"we made no protest against the CPO at the public inquiry...it's difficult due to the power of the people applying it" (pg 1411).

The authors report that the latter group were less bitter about the process as a whole. For the authors, this is an "interlinking of legitimacy, and authority, with legality" which they argue "was one of the powerful underpinnings of the process" (pg 1409). The theory of autopoiesis would interpret this as the operation of the binary code of the legal system in securing 'timebinding' and thus conditioning expectations.

The authors review the literature on the social interpretive view of law and cite authors, including Chouinard (1994), Blomley, (1994), Pue, (1990) and Kobayashi (1990), whose work evidence this position. They quote Chouinard who argues that "the course and outcome of legal processes is uneven" (Chouinard, 1994, p.435 quoted in Imrie and Thomas, 1997, p.1405) and build upon work by others to argue that

"for Blomley, and others, the importance of geographical specificity lies in its challenge to legal conceptions of spatial uniformity and of a world 'peopled by an abstract homo judicus' (Blomley and Clark, 1990, p.441). Thus, geographical contexts display a richness and complexity of legal subjects, contrasting lifestyles and moral worlds which conjoin in contesting what Pue characterises as the "ambiguity and incoherence of legal rules" (Pue, 1990, p.572 quoted in Imrie and Thomas, 1997, 1405).

In contrast to the above argument, in this case, we have noted how the Law operates on contingent circumstances, but with certainty with regard to the strict operation of the legal code. If we accept the strict operation of the legal/illegal code, the next question must inevitably arise: how then does the legal system operate in relation to other functional systems?.

The public inquiry alluded to earlier is a creation of the structural coupling of the political and legal functional systems. Public hearings take place through the Planning Inspectorate. Here, the Inspector, who reports to the Secretary of State (a political functionary), takes a decision to approve/not approve an appeal. This decision is outside the jurisdiction of the law itself, but can become part of it through an appeal to the High Court, but only if there is a claim to mis- 
interpretation of the law. The Inspector thus though primarily influenced by policy or political decisions (being part of the political apparatus), has to also ensure that the decisions made are legal or else risk a challenge in the courts where the strict binary code of the legal system will apply. The institution of the Planning Inspectorate thus manages the 'irritation' of the legal system on the political system. The authors report that one company termed the process as "the farce of the public inquiry" (pg 1410), while another concluded that "the judge and the jury were one and the same" (pg1411). Further, "the CPO was characterised by a minimalist interpretation by the LAW of their legal duties and obligations..." (pg 1409). All of the above are testimony to the politico-legal function of the Planning Inspectorate. The Planning Inspectorate is however an institution solely created by the political system to manage the irritation from the legal system. The Inspectorate does not form part of the legal system, nor is it structurally determined by it. The irritation of the legal system on the political system has therefore led to greater internal structural complexity of the political system in order to manage certain kinds of constant perturbations on it. As suggested by the theory of autopoiesis, what we see here therefore is the increase of internal structural complexity of a functional system, solely determined by itself, in order to deal with perturbations from another functional system.

The legal system also 'irritates' the political system in other ways. One instance of this in the case study, is through the speed of the process. The political system uses its power (the binary code is power/no power) to speed up the process in order to reduce the risk of litigation for then matters might move into a functional system, whose decisions it cannot determine. 'Speed of the process' is therefore a 'conditional programme', a response of the political system to the perturbation of the legal system, of the form 'If speed, then no litigation' The authors point out

"In relation to the regeneration of Atlantic Wharf, the overall regeneration scheme was sponsored by the local authority and the underlying approach of the statutory authorities was to "get the job done quickly"' (pg 1408).

This speed is manifested in the specification of tight deadlines. The political system in turn thus perturbs the legal system by creating deadlines through a 'legal process'. The impossibility of the speed then is not a consideration for the legal system as it only considers the legality of the setting of deadlines. The authors report:

"for many firms the process effectively criminalised them in that they felt unable to respond to the short deadline that had been set" (p. 1409).

"firms who broke the timetable were not seeking to break the law per se (yet in effect this was what they did), but were reacting against what they perceived were the impossibilities of the legal strictures that had been placed on them" (pg 1409, original brackets). 
Another example of the perturbation of the political system on the legal system is through the use of media as evidenced in the following quote from the Editorial of a local newspaper:

The ambitious and imaginative South Glamorgan County Council scheme to transform the Butetown Dock at a cost of $£ 100$ million represents a renewal of interest in the water and the enormous potential it represents (Soth Wales Echo, 18, May, p.8, quoted in Imrie and Thomas, 1997, pgs 1408-1409).

The authors speculate that stories of positive imagery including artists' impressions were probably 'fed' to the newspaper by the South Glamorgan County Council.Reactions from local councillors and council officers were also published in the coverage. The use of the media is also then another form of conditional programming within the political system of the form 'If positive image, then no legal action'. The authors conclude -

"so complete was the hegemony of this view that even the landowners who objected to the CPO still subscribed to the vision of 'progress' which underpinned it..." (pg 1408).

The perturbations that are produced by other functional systems mean that what is legal or illegal in the future can become quite blurred. Autpoiesis tells us that the legal system, though assuring the operation of the legal/illegal code and thus time-binding expectations of society in general, cannot characterize any particular event or individual action as legal or illegal in the future. It cannot specify the complex web of contingencies that may occur in the future or set the rejection values and programmes that may come into play. Thus, decisions of legality/illegality by the legal system will always only be made in the present and cannot be known beforehand, what can be predicted is only the application of the code of legal/illegal.

The law was portrayed as failing expectations of some property owners. The authors report that these property owners then "became cynical" (pg 1411). The firms expected the legal system to be more 'fair'. The authors cite the instance of a firm that was more "optimistic in the fairness of the legal system.... It will see us right and take care of our needs" (pg 1411). We have seen earlier, that within the theory of autopoiesis, justice or 'fairness' is a formula used by the autopoietic system to ensure 'equality' across programmes. The equal/not equal code allows the legal system to re-programme or create new programmes to ensure 'equality' across programmes. If brought to the legal system, it can rule the noted speed of execution as illegal if, and only if, this violates the 'equality' of its own previous operations. The legal system similarly cannot mediate the political use of media unless this violates the legal system's own 
previous operations. Through 'self-observation' the legal system would introduce a 'rejection value' and rule such mediations as not eligible for the application of the legal and illegal code. An 'equality' across decisions is necessary in order for the legal system to maintain equality with previous decisions. 'Justice' is the 'formula' that the legal system uses to maintain equality across decisions. It is the norm by which like situations are treated alike. Thus, as far as the legal system is concerned, the operations are 'just' as long as it maintains 'equality' with previous operations.

We have seen above that the legal system, though self-referential and operating on a strict binary code, is still nevertheless constantly perturbed by other systems and perturbs other functional systems. This does not change the application of the code or the self-referentiality of the functional systems. It might however result in structural change within the functional systems concerned and can lead to new institutions or programmes. The functional systems also maintain a 'rejection value' wherein it decides if an event or decision is a concern for the system. Within the legal system 'justice' provides a norm that is used to maintain 'equality' across decisions.

\section{Implications of Legal Autopoiesis for Planning}

The above reinterpretation of a published case study was adopted primarily to present and illustrate the theory of autopoieis, and how it might reinterpret a given situation in order to reveal different insights. There are two implications for planners arising from such a reinterpretation. The first is the epistemological significance of the theory and therefore the message it gives to planners. The second is the analytical significance of the theory and the contribution that it thus makes to the profession. This section below discusses these.

The implications of autopoiesis for epistemology is one of its most radical contribution. The theory argues for the impossibility of arriving at final statements as any statement can only be made from a position with its associated viewpoint. Yet, autopoietic systems theory itself advances a certain type of conception about the world, which is posited as 'real' and universal for all functional differentiated modern societies. Luhmann's autopoiesis has thus given rise to a new position, - 'radical constructivism' - a term coined by a cognitive psychologist, Ernst von Glaserfeld (Knodt, 1995, pg Xv). For planners, the significance of this is that it reflects an epistemology that "leads to a radical constructivism and to the generation of realities without obligation for consensus" Luhmann (1997b, pg 369). This offers great political promise as it 
"offers hope that a world that is contingently constructed can also be differently constructed" (Rasch and Wolfe, 2000, p. 7, original emphasis).

Planning is a discipline guided by goals/visions often claimed to be in the public interest. The epistemological significance of the theory then problematizes a 'consensus' notion of the public interest, without entirely negating it. It tells us that any event or action claimed to be in the public interest, will be observed very differently by the functional systems thereby triggering different responses in each. Any decision will be processed by the legal/illegal code within the legal system, the money/no money code of the economic interest and the power/no power code of the political system. Claims for the public interest then on whatever normative grounds, can always only be an interest differently aligned with particular functional systems even when there seems to be an apparent consensus. This explains the 'fragility of consensus' often highlighted in the literature (Selman, 2010, Allmendiger and Haughton, 2010).

The situated nature of planning is well accepted today, but autopoiesis infuses this situatedness with a degree of stability. For instance even when the contingent circumstances will vary, the operation of the strict self-referential binary code of the functional system is stable. This gives us a set of meta-operations that can help the planner's orientation in the situatedness of contingency. The operation of this stability within contingency can be understood as the operational parallel of 'constitution and post-constitutional problems' that Moroni (2018), sets out for normative questions concerning conflict, public interest and private property. Moroni argues that normative questions can only be resolved through a multi-level approach wherein, for instance, consensus is required at the constitutional level even when conflict is admitted in post-constitutional levels; public interest at the constitutional level might evoke the interest of potentially everybody while at the post-constitutional level might still be against the interests of particular groups; and the right to hold property at the constitutional level does not necessarily mean that every person holds a title at the post-constitutional level. Similarly, the theory of autopoiesis suggests that there are mechanisms and operations that can be described at a meta-operation level, even when the contingent manifestation of these operations may vary. In the case above we therefore see the predictable self-referential binary operations of the legal system and the political system, the institutional and programmatic mechanisms for structural couplings of functional systems and the concept of 'justice' understood as equality through which the legal system operates to bind expectations across time. Understanding this 
stability within contingent variety, in terms of mechanisms and operations then helps planners orient themselves not normatively, but in relation to questions of ' $h o w$ '.

\section{Conclusions}

This article has described the theory of autopoiesis and its approach to the analysis of social systems. In particular, it focused on the legal system in its interactions with planning. The strict self-referentiality enables a system to cognitively reduce the complexity in the environment and acquire requisite internal variety and structural complexity in order to interact with the environment. Differentiation is one way in which social systems acquire this requisite variety. By differentiating into functional sub-systems the social system as a whole acquires the internal structural complexity to effectively interact with the complexity of the environment. In modern societies, functional social systems such as the legal system, economic system, and so on are operationally closed in that they operate on a binary code. They are however cognitively open to the environment which consist of other functional systems, psychic and biological systems.

The theory is rather abstract and difficult to understand as it often uses concepts in an unusual way which does not resonate with the normal understandings associated with the terms. In order to introduce and illustrate the theory, a secondary case study was employed. The case study described the implementation of the Compulsory Purchase Order in the regeneration of the Docklands in Cardiff in the UK. This published case study is well described and supported with evidence. It also advances claims based on socio-legal theory following an interpretive paradigm, which is distinctly different from the claims of systems theories. This contrasting perspective made the article a good vehicle to showcase the differences in claims and the implications that followed.

A selection of concepts from legal system theory was introduced and discussed. These involved the idea of the binary code, the play of a rejection value, programming to incorporate flexibility, structural coupling with other functional systems and the meaning of justice in systems theory. The case study summarised earlier was then re-interpreted using the concepts. The reinterpretation highlighted the operation of the binary code in the case study; the mechanisms of structural coupling between functional systems; the use of programmes by functional systems to attain flexibility; and the operational interpretation of justice within the legal system. 
Evidence of the above dynamics were then used to argue for two important contributions to planning thought relating to a) epistemology and b) meta-operations that can guarantee a degree of stability in contingent circumstances. Epistemologically, the theory adopts a 'radical constructivist' perspective on functional lines emphasising the position of the observer in any narrative. For planners, the theory insists on universal mechanisms that are nevertheless unpredictably realised in contingent circumstances. There is thus stability in meta-operations even within contingency. To conclude then, the theory deconstructs 'how to' dilemmas for planners by revealing new explanations for mechanisms, institutions and the purpose they serve from a non-normative standpoint within neo-systems thinking.

\section{References}

Allmendinger,P and Haughton,G (2010) Spatial Planning, Devolution, and New Planning Spaces. Environment and Planning C, 28(5), 803-818.

Blomley,N and Clark,G (1990) 'Law Theory and Geography' Urban Geography, 11, pgs 433-446.

Blomley,N (1994) Law, Space, and the Geographies of Power, Guildford Press: London.

Booth,P (2002) 'From Property Rights to Public Control' In Town Planning Review, Vol 73(2) pgs 153-170.

Booth,P (2003) Planning by Consent. Routledge: London.

Chettiparamb, A. (2007a) 'Re-conceptualising Public Participation in Spatial Planning - A

View through Autopoiesis' Planning Theory, 6(3), 263-281.

Chettiparamb, A. (2007b) 'Dealing with Complexity - An Autopoietic View of the People's

Planning Campaign, Kerala' In Planning Theory and Practice, 8(4), 489-508.

Chouinard,V (1994) 'Geography, Law and Legal Struggles: Which Ways Ahead?' In Progress in Human Geography, 18, pgs 415- 440.

DCLG (2004) Compulsory Purchase and Compensation: Compulsory Purchase Procedure. Office of the Deputy Prime Minister: London. Available at https://assets.publishing.service.gov.uk/government/uploads/system/uploads/attachment data/file/571449/booklet1.pdf (Last accessed 14-05-2018).

Gumbrecht,H,U (2001) 'How is our Future Contingent? - Reading Luhmann Against Luhmann' In Theory, Culture and Society Vol 18 91). Pgs 49-58.

Herbert-Young,N (1998) 'Central Government and Statutory Planning Under the Town Planning Act, 1909' In Planning Perspectives 13(4) pgs 341-355.

Imrie, R and Thomas, H, (1997) 'Law, Legal Struggles and Urban Regeneration: Rethinking the Relationships' In Urban Studies, Vol 34 No 9, Pgs 1401-1418.

King, M and Thornhill,C (2003) Niklas Luhmann's Theory of Politics and Law. Plagrave Macmillan: Basingstoke.

Knorr-Cetina,K (1981) 'The Micro-sociological Challenge of Macro-sociology: Towards a Reconstruction of Social Theory and Methodology' In Knorr-Cetina,K and Cicourel,A.V (eds) Advances in Social Theory and Methodology - Towards an Integration of Microand Macro- Sociologies Routledge \& Kegan Paul: London

Kobayashi,A (1990) 'Racism and the Law in Canada: A Geographical Perspective', Urban Geographhy, 11, pgs 447-473. 
Luhmann,N (1991) 'The Coding of the Legal System'. In Teubner,G and Febbrajo,A (eds) State, Law and Economy as Autopoietic Systems - regulation and Autonomy in a New Perspective Dott.A.Giuffre Editore: Milan

Luhmann,N (1992) Beobachtungen der Moderne. Opladen:Westdeutscher Verlag.

Luhmann,N (1995) Social Systems Translated by Bednarz,J Jr with Baecker,D Stanford University Press: California

Luhmann,N (2004) Law as a Social System. Translated by Klaus A Ziegert. Oxford University Press: Oxford.

Moroni,S (2018) Constitutional and post-constitutional problems: Reconsidering the issues of public interest, agonistic pluralism and private property in planning. Planning Theory, Online First. https://doi.org/10.1177/1473095218760092.

Nobles,R and Schiff,D (2004) Introduction. In Luhmann,N (2004) Law as a Social System. Translated by Klaus A Ziegert. Oxford University Press: Oxford.

Nobles,R and Schiff,D (2013) Legal pluralism: A Systems Theory Approach to language, Translation, and Communication. In Freeman,M and Smith,F (eds) Law and Language: Current legal Issues, Volume 15, Oxford University Press: Oxford. Pgs 100-114.

Paterson, J (2006) Reflecting on Reflexive Law. In King, M and Thornhill,C (eds) (2006) Luhmann on Law and Politics: Critical Appraisals and Applications. Hart Publishing: Oxford. Pgs. 13-35.

Pue,W (1990) 'Wrestling with Law: (geographical) specificity versus (legal) abstraction, Urban Geography, 11, pgs 566-585.

Riley,J (2009) 'Well-being and the democracy of compulsory purchase'. Journal of Place Management and Development. 2(3), 230-239.

Salet,W,G,M (2002) 'Evolving Institutions - An International Exploration into Planning and Law' In Journal of Planning Education and Research, Vol 22, pgs 26-35.

Selman,P (2010) Multi-functional Landscape Plans: A Missing Link in. Sustainability Planning? Local Environment, 7(3), 283-294.

Van Assche.K, Beunen.R, Duineveld,M and de Jong, H (2012) Co-evolutions of planning and design: Risks and benfits of design perspectives in planning systems. Planning Theory, 12(2), 177-198.

Van Assche,K and Verschraegen,G (2008) The Limits of Planning: Niklas Luhmann's Systems Theory and the Analysis of Planning and Planning Ambitions. Planning Theory, 7(3), 263-283. 